\title{
Evolution and competition in the market for handheld computers
}

Citation for published version (APA):

van Wegberg, M. J. (1998). Evolution and competition in the market for handheld computers. NIBOR, Netherlands Institute of Business Organization and Strategy Research. NIBOR Research Memorandum No. 04 https://doi.org/10.26481/umanib.1998004

Document status and date:

Published: 01/01/1998

DOI:

10.26481/umanib.1998004

Document Version:

Publisher's PDF, also known as Version of record

\section{Please check the document version of this publication:}

- A submitted manuscript is the version of the article upon submission and before peer-review. There can be important differences between the submitted version and the official published version of record.

People interested in the research are advised to contact the author for the final version of the publication, or visit the DOI to the publisher's website.

- The final author version and the galley proof are versions of the publication after peer review.

- The final published version features the final layout of the paper including the volume, issue and page numbers.

Link to publication

\footnotetext{
General rights rights.

- You may freely distribute the URL identifying the publication in the public portal. please follow below link for the End User Agreement:

www.umlib.nl/taverne-license

Take down policy

If you believe that this document breaches copyright please contact us at:

repository@maastrichtuniversity.nl

providing details and we will investigate your claim.
}

Copyright and moral rights for the publications made accessible in the public portal are retained by the authors and/or other copyright owners and it is a condition of accessing publications that users recognise and abide by the legal requirements associated with these

- Users may download and print one copy of any publication from the public portal for the purpose of private study or research.

- You may not further distribute the material or use it for any profit-making activity or commercial gain

If the publication is distributed under the terms of Article $25 \mathrm{fa}$ of the Dutch Copyright Act, indicated by the "Taverne" license above, 
Abstract. Since the early 1990s, electronic organisers or electronic agendas have been evolving towards fully fledged, but miniature, computers. This paper is a case study about this market. Uniquely, and reminiscent of the home computer market in the 1980s, this is a market for personal computers not dominated by Microsoft. Or at least, not yet. In tracking the evolution of this market, the paper points especially to the importance of networking and standardization. The market for handheld computers is a small market, compared to the units shipped in the market for PCs. Nevertheless a surprisingly large number of vendors has been and still is active in this market. During the short history of this market, there have been several periods where technological breakthroughs created expectations of huge growth, with entry by new suppliers as a result. As the dust settled, the losers either changed strategy, or left the market altogether. The paper will argue that standardization and networking are major factors in explaining competitive success and the recent growth of the industry.

${ }^{1}$ Faculty of Economics and Business Administration, University of Maastricht, P.O. Box 616, 6200 MD Maastricht, The Netherlands, tel. +31 43-3883654, fax. +31 43-3258495, e-mail: M.vanWegberg@MW.UniMaas.nl, home page: http://www.unimaas.nl/ mwegberg/index.htm 
Handheld computers are light, small computers that users tend to carry with them. They started out as electronic organizers similar to pocket calculators, and they have evolved into fully-developed computers. This dramatic development in such a short time is an achievement that calls for closer study. A surprisingly large number of firms has contributed to this development. Many have been attracted by outrageous predictions concerning huge growth expected of this market. Many have been disappointed by what is still very much a niche in the computer market. The market is still very experimental, and far from mature. Competition in this case is linked to standardization issues. Standardization of handheld technology has the nice characteristics that it both reduces (adaptation) costs for suppliers and increases product quality (functionality) for users. Both forces drive the evolution of this market. Observers believe already a number of years that its take-off is close by.

This paper will try to identify the developments and strategies that shaped the evolution of the handheld computing market. It features a case study of this market with a record of its history. It also discusses the standardization process, and identifies the business strategies of its participants.

2. Theoretical perspective

The theories that will (implicitly) guide the analysis in the paper are the Industrial Organization theories of competitive advantage and, more particularly, game theoretic analyses of alliances, entry barriers, multi-market competition, and standardization. Van Wegberg (1996) contains an integration of these theories that helps to explain competitive success in a market where cooperation and standards are very important.

The core idea is that firms and customers form networks. Participants in a network exchange values with each other. These values can be inputs or commodities, as in a value-added network, or know how, information, or social values, such as recognition and reputation. In economic theory, a network is linked to externalities. There is a network if exchanges take place of values without a price being quoted for them. The reward of a particular contribution in an exchange can be the hope for a reward in the future. If the network is efficient, it allows for an exchange of values that would not take place if transactions were limited to (more or less) perfectly competitive markets. ${ }^{2}$ A network tends to evolve over time as participants in some kind of exchange begin to recognize each other's interdependence.

The handheld computer market shows an evolution towards networking. From an economic perspective, a network will come to exist if there is a positive network externality. A concise definition of this concept is:

'Positive network externalities arise when a good is more valuable to a user the more users adopt the same good or compatible ones.' (Tirole, 1988, p. 405)

\footnotetext{
${ }^{2}$ The point is well taken that the boundary between an imperfectly competitive market, where participants may form a cartel, and a network, is difficult to identify.
} 
There are various explanations, both on the supply side and on the demand side, for the positive externality. In a market, networks may exist at three levels:

SUPPLIERS: suppliers cooperate with each other for various objectives, such as to develop technologies, or to enter a new market. Firms may cooperate with buyers, suppliers, rivals, etc. The aim of cooperation can be to provide (develop, produce, or market) those products that, if used together, create a positive externality as mentioned by Tirole.

- CUSTOMERS: customers may benefit from interacting or coordinating with each other. They communicate with each other, trade, exchange social values, etc. It may take some product or technology to participate in a particular network, e.g., a telephone buys the customers access to the telephone network. The more customers buy a product that gives access to a particular network, the larger the utility of the product tends to become (this is the positive externality).

TECHNOLOGY: a technology is a network if it consists of autonomous nodes that are linked (e.g., Tanenbaum, 1997). Examples are telecommunication, computer data communication, and energy and transportation networks. The Internet turned isolated computers, such as home computers, into access terminals for a worldwide information and communication network.

In Information and Communication Technology (ICT) industries, networks are closely linked to standards. Standards are technologies that combine products or components in a complex entity that can produce a service to the users. The components used can be hardware or software. The users may be end users or business users. The reason that these technologies are called standards is that they require certain conditions which must be met for the service to be provided. Those conditions (often rather than the technologies themselves) are the standard.

Standards are economically important for various reasons. A standard may define a set of conditions that can provide a new service. Hence, they play a crucial role in innovation; they create or enlarge markets (the market creation motive). Firms whose technologies meet the standard have a competitive advantage relative to rivals who have to incur costs, or whose customers have to incur costs, before they can meet these conditions. The ability to define standards is thus a factor in competition, by which firms can reduce their own costs or impose costs on (potential) rivals (the market power motive).

Standards are important if they are able to couple existing components in a new way, to create new functionality. Coupling components increases the complexity of a system. A complex, interdependent sytem tends to be relatively inert, as a change in one part requires changes in other parts. The required degree of coordination tends to slow down adaptation. In order to participate in a dynamic process, firms have since the 1980s began to create modular systems. A modular system combines complex interdependence with dynamics. See Vercoulen and Van Wegberg (1998) for a review of this literature. A modular system splits up a system into separate entities (modules) which are coupled by means of standard interfaces, gateways, or other connections. Each module provides a standardized (predictable) service to the overall system or product. The architecture is the set of design specifications (standards) that determines the link between modules. How a particular module functions 'internally' is a different matter, that falls beyond the scope of the architecture. Modularity is linked to division of labour in two ways: technically, the 'work' of a product is split up over various modules, and economically, various companies can collaborate, each by specialising in (developing or producing) one or more modules. 
The analysis in Henderson and Clark (1990) has shown that a modular system consisting of an overall architecture and individual modules can show the following four kinds of dynamics (see the table).

\begin{tabular}{|l|l|l|l|}
\hline \multicolumn{2}{|l|}{ Dynamics in a modular world } & \multicolumn{2}{|l|}{ Changes in Modules (new modules, improvements) } \\
\cline { 2 - 4 } & No & Yes \\
\hline Changes in architecture & No & No (or incremental) & Modular innovations \\
& Yesange & Architectural & Radical innovation \\
\cline { 2 - 4 } & innovations & \\
\hline
\end{tabular}

The table shows that if an architecture is not flexible enough to accommodate new modules, a radical innovation may occur. New architectures emerge to incorporate new modules.

These are some theoretical notions that, as we will see, are quite relevant for the market for handheld computers.

3. The market place

Handheld computers are a segment in the personal computer market. They range from electronic organizers with a limited, and fixed, functionality to fully-fledged, programmable, if small, computers. They are obviously distinct from calculators, although they share some common technology, and have historical ties. A subnotebook is a small portable computer. The distinction between a handheld and a subnotebook is difficult to draw. Somewhat arbitrary, a subnotebook can be defined as a portable computer about the size of an A5 paper, and weighing close to or more than a kilo. Computers smaller than that do fit in a hand, and can be called handhelds. In this paper, I will treat the handheld market as a single market. Some observers subdivide the market in organizers (very small, limited functionality, the user cannot add or modify the software) and PDAs (intelligent programmable computers). Or, alternatively, they distinguish machines that have a keyboard from those that do not, and are operated by 'writing' with a pen over a touch screen, aided perhaps by handwriting recognition. I will regard these distinctions as aspects of the product line and the technologies used rather than as different markets.

A handheld computer consists of various components. These include the case, a processor, batteries, computer memory, an Operating System, applications, human interface (handwriting recognition, word prediction, voice recognition), connectivity to the $\mathrm{PC}$, printer or other products. The applications turn the 
machine into an organizer, such as an agenda, names and addresses, alarm, note taker, and a list of to dos. They may also contain extras such as a voice recorder, world clock, wordprocessor, spreadsheet, etc. I will focus on those components that are under the control of the vendors themselves, that is, the operating system, applications, human interface, and the connectivity.

Some information on the market is in order before we turn to the technological turmoil. The source for my data, directly or indirectly, is the research company Dataquest. It estimated sales of handheld computers at (source: Dataquest, May 3, 1995, Business Week, 9-9-1996):

$\begin{array}{lll}\text { Year } & \text { Sales in } 1000 \text { units } & \text { Growth }(\%) \\ 1993 & 684 & \\ 1994 & 950 & 39 \\ 1995 & 1,200 & 26 \\ 1996 & 1,500^{3} & 29 \\ 1997 & & 65\end{array}$

Dataquest (quoted in Automatisering Gids, 20-6-1997) estimates the worldwide market shares (in percent) of the market leaders in 1996 as follows:

$\begin{array}{ll}\text { Sharp } & 28 \\ \text { Psion } & 25 \\ \text { U.S. Robotics } & 24 \\ \text { Hewlett-Packard } & 12\end{array}$

How volatile this market is, can be concluded from the fact that U.S. Robotics achieved this third place in the very first year that it was active in this market! Dataquest estimates that sales of Windows CE handhelds in 1996 (which was their first year) were just over 20,000 units. The Dataquest (1997) report suggests that the entry by U.S. Robotics' Palm Pilot in 1996 had two effects: it strongly increased the overall demand for handhelds and it reduced the market share of the other suppliers. For an example of the competition effect, look at Psion. The absolute level of units shipped in 1995 would have been 1.2 million according to Dataquest (Business Week, 9-9-1996) while Psion is reported to have sold 350,000 units in that year (The Economist, 6-7-1996). This suggests that in 1996 Psion's market share decreased from $29 \%$ to $25 \%$.

Analysts expect the double digit growth rates of the market to continue. For instance, in a report summary downloaded on 20-7-1998, the research bureau Semico expects aggregate turnover in the handheld market (including smartphones) to reach $\$ 7.5$ billion by $2003 .^{4}$

${ }^{3}$ This figure is my estimate from a graph in a Dataquest report Fall 1997 Handheld Report: 1996 Results and Other Developments.

${ }^{4}$ To put this prediction into perspective, I estimate revenues in 1997 as 2475000 units being sold (a $65 \%$ growth over 1,5 million units in 1996), at a price of say, on average, $\$ 500$. This would imply total revenues in 
The market for handheld computers roughly developed through three stages.

1.

1989-1992: Electronic organisers

Late 1989, Atari introduced its Portfolio handheld computer (Personal Computer World, May 1998, p. 94). Using MS-DOS, this fairly bulky machine featured agenda and note-taking functions, as well as some computerlike functions, such as a spreadsheet. In 1990, Hewlett-Packard sold a calculator which had some agenda functions. Japanese suppliers developed electronic organizers, the Casio BOSS and the Sharp Wizard series. Their machines were small, with tiny keyboards, puny screens, and small memories. The limitations imposed by their hardware, limited these machines to just a few functions: agenda, a contacts database of names, address, telephone numbers, an alarm, and a note taker. They were an electronic variety to the paper-based agenda. The value added of an electronic organiser over a paper agenda is limited to the possibility of sounding an alarm and using a search function. Moreover, unlike an agenda, the electronic organiser is not limited to a useful life of one year. Understandably, given the existence of very cheap paper substitutes, the market for these machines was very limited.

Notable entry into the handheld market came in 1991 from Hewlett-Packard and the British company Psion. HP introduced its HP 95 LX, a small micro based on MS-DOS with a full version of Lotus 1-2-3 embedded. In late 1991 Psion introduced the Psion 3. Technically, it derived from Psion's MC series of subnotebooks (introduced in 1989). Taking their cues from the Atari Portfolio, the HP 95 LX and the Psion 3 pioneered the concept of the handheld as a fully-fledged computer, with a decent keyboard, built-in programming language, wordprocessor rather than a mere note taker, generic database, and spreadsheet. Both products became icons of the handheld market, spawning long-term success for their suppliers.

2 .

1993-1996: Experiments

The year 1993 was a turning point in the evolution of the handheld market. Various experiments saw the light of day. The best known experiment was the Apple Newton. It pioneered a new user interface, that included

1997 of $\$ 1.2375$ billion. To achieve aggregate revenues of $\$ 7.5$ billion in 2003 , which is six years later, would require an annual growth rate of $35 \%$. This is quite a lot, even by computing standards. 
handwriting recognition and intelligent user-friendly software. The use of a touch screen allows the user to point at commands rather than type them, and it allows her to scribble drawings on the screen. Hence, the similarity to a notebook or agenda actually became more real with this approach. Apple launched the concept of personal digital assistant (PDA) for her product. It claimed that the PDA's functionality had strongly increased over the first generation of electronic organizers and notetakers.

Another kind of experiment was the personal communicator that integrates voice and data communication functions, such as a mobile telephone or e-mail, with a handheld computer. Examples of these hybrids were AT\&T's EO, IBM's Simon, and Motorola's Marco. These products represented the vision that managers need to be in touch with their office while on the road. Up to the present day, this vision drives many vendors and innovators in this market. What the first generation personal communicators tried to do is translate that vision into a feasible product. This is where they stumbled.

Alongside with these forms of a revolution, there was also evolution. The pioneers Casio and Sharp continued to improve their first generation product line. They also tried to keep in touch with these experiments by participating in them by means of separate product lines. For example, Sharp improved its proprietary Wizard series with some new technology, such as touch screen, while it also supported Apple in developing and manufacturing the Newton. Casio likewise continued its proprietary system, while hooking up with Tandy to introduce a separate product, the Zoomer, a pen-based PDA that was very similar to the Apple Newton. The larger flexibility of the second generation handheld computers, compared to the first generation, indicated the extent to which the computing power available to small machines had increased. This underlying trend of miniaturization is an obvious driving force in the handheld market.

HP and Psion, in the meantime, continued to refine their existing product line. Psion, notably wary of experiments, continued on its Psion 3 theme by introducing the Psion 3a. The Psion 3a followed the HP by including a spreadsheet and by increasing the screen size. The result was a powerful computer in a very small case.

3.

1996 -: Connected Computers

The experiments in the period since 1993 were commercial failures. The evolutionary approach by the stalwarts Casio, HP, Psion and Sharp continued, without leading to a breakthrough in growth or market share. This created a window of opportunity. In 1996, two companies jumped in and both succeeded in grabbing a large market share. U.S. Robotics (later acquired by $3 \mathrm{Com}$ ) launched the minute PalmPilot handheld computer, and Microsoft finalised Windows CE, its operating system for handheld computers. As we will see, both entries were based on a considerable amount of expertise built-up during the previous period, the experimental phase. Some companies reacted by exit from the industry, including Apple, while others converted to the Windows CE system (such as the stalwarts Casio, HP and Sharp). A year later, Psion reacted to these entries by the Psion Series 5, which contains a 32-bit OS as compared to the 16-bit operating system of the Series 3.

The recent developments in the field characterise handheld computers as fully functional, up-gradable, computers, with mature, 32-bit, operating systems. They improve on the second generation handheld computers 
in several ways. Some practicable forms of handwriting recognition are introduced. They also introduce new functions, for instance, some include a microphone, so they can be used as a voice-recorder.

Another improvement is that handhelds become better connected to the information and information appliances that people carry around or use in their work. Microsoft's Windows CE especially targets users who also have a Windows 95 computer. Other systems too, such as the PalmPilot from $3 \mathrm{Com}$ and the Psion 5 series, offer a degree of connectivity with the PC that markedly exceeds the first and second generation handhelds. This also reflects a change in the PC itself: since the public appearance of the Internet by about 1994, users increasingly use the PC for e-mail. They began to store on their PC the kind of contact information (names of people with their e-mail addresses etc.) that they also store on handheld computers. To prevent re-typing of information, they want to synchronize information between the PC and the handheld computer. Since 1996, handhelds respond to this need.

Nokia followed a different approach, by embedding a handheld computer in a GSM mobile telephone. In 1996 it introduced its hybrid computer / phone, the Nokia 9000 Communicator, which is a second generation attempt to develop a personal communicator or smartphone.

These products make it clear that the underlying trend is connectivity of the handheld to a range of products: the PC, the mobile telephone, a GPS global positioning system for (car, truck or boat) navigation, and a digital photo camera. The latter innovation, introduced by Sharp, connects a small digital camera to a Windows $\mathrm{CE}$ handheld computer. The screen of the handheld serves as viewfinder, its storage capacity stores the picture, and its connectivity to the PC can be used to display or process pictures on the PC. What consumers seem to need is not portable computers, but portable information: easy access where ever they are to the information they need.

Which business strategies led to the evolution of the handheld market, and how did firms in turn react to developments? Specialization is the first aspect of a strategy that we will encounter. The subsequent paragraphs will identify other aspects of strategy that affected the evolution of this market.

5 .

Specialization in fardware and software vendors

The market for handhelds consists of two, increasingly separate markets: for software and hardware. In the early stages of the market, each system and each vendor had its own operating system and application software. Software was proprietary, and specific to its vendor. Sharp and Casio excelled in the organizer market with this approach, witnessing their Wizard and BOSS product lines. The advantage of this integrated design approach is that all components can be made to fit together perfectly. This was probably the appropriate strategy in this early stage. Since the computing resources embedded in an organizer were extremely limited, the dominant design imperative was to have a tight fit between the elements to optimally utilize these resources.

The increasing level of computing resources allowed manufacturers to improve the quality both of the hardware and the software. This increases the returns to specialization. As a result, the development of hardware and software became separated.

Specialization initially took the form of vendors licensing their software to (potential) rivals. This allows the licensees to specialize in manufacturing and marketing the end product. This is how Apple, Psion, and 
3Com try to involve other vendors in supporting their system. Sharp, for instance, introduced a handheld computer using Apple's Newton software. The Geofox upstart company sells a handheld using Psion's EPOC32 software. And IBM sells its WorkPad handheld computer, which is identical to the Pilot from 3Com (which acquired U.S. Robotics). There are two difficulties with this business model.

The first problem about licensing is a need for trust. The licensees cooperate with a software supplier, who is also a rival in their market. If, just to mention an imaginary example, Geofox's handhelds would successfully compete with Psion's, Psion might be tempted to stop licensing its software to Geofox. This is no contrived fear. In 1996 and 1997, Apple licensed its Macintosh operating system. Most licensees were upstarts, such as Power Computing and Umax, with Motorola being the only established firm to sell Mac-compatible PCs. Apple thought it had little to fear from these self-invited rivals. When it discovered, however, that they successfully competed Apple out of its market, it closed down its licensing program by the end of 1997 (Byte, Aug. 1996 and Nov. 1997). The result: Power Computing and Motorola had to close down a large part of their new business. The fear that this may also happen in the market for handhelds may keep firms from licensing software from existing vendors of handheld computers.

Another problem about licensing is that an operating system such as the Palm OS is very tightly linked to the Pilot computer. The OS 'knows' that there is no keyboard, no permanent storage (such as a PC card), no sound, and that the screen contains $160 * 160$ pixels. This makes it very difficult for licensees to differentiate their product from the original 3 Com Pilot. This is an example where modularity (the separation between hardware and software) plays not just a technical but also an economical role. A licensing business model thus needs two things: a vendor with a reputation for not ripping off licensees and a modular operating system. Both conditions are more readily provided by software developers who do not develop, manufacture, and market end products. This calls for a more extreme form of specialization, when a company dedicates itself exclusively to developing either software or hardware. General Magic, Geoworks and Microsoft are the three pure sellers of operating systems in this market. Their customers focus exclusively on making and marketing the hardware. They license their software to hardware manufacturers, such as Hewlett- Packard, Nokia and Philips. We will look at these software specialists in more detail.

$$
\text { 1. General Magic }
$$

General Magic was created in 1990 by ex-Apple employees as an Apple spin-off to develop a hand-held for writing and sending electronic messages (Byte, Sep. 1990). At its inception, there were speculations its product would accept handwritten input. As Byte (Sept. 1990) succinctly notes: "They have a vision; now they need time to develop it." By 1993, General Magic had attracted a respectable group of companies to support it: Apple, AT\&T, Matsushita, Motorola, Philips and Sony. By 1994, its supporters also included Fujitsu, Mitsubishi, Northern Telecom, NTT, and Toshiba. General Magic was now working on two products: an operating system called Magic Cap and a telecommunication scripting programming language Telescript.

In 1994, the first product appeared on the basis of Magic Cap: Motorola's communication handheld, the Envoy. It was followed a year later by the Sony Magic Link PIC-1000. Both products are not really independent handheld computers, rather they give access to computer data networks. These include AT\&T's PersonaLink 
network, which was accessible only by these products, and America Online's data network (which at the time was similar to but different from the Internet). This combination of network and network access products did not come off the ground, and AT\&T closed down its PersonaLink service in 1996. One reason for this may be the sudden ascendancy of the Internet, which left alternative communication technologies such as Telescript in the dust. As a result, the Magic Cap operating system is currently (in 1998) without products that are actually available in the market.

In 1996, General Magic shifted its focus from software for the handheld computers to the Internet. In the period from 1990 to 1996, it had lost a cumulative amount of \$74 or \$78 million (Automatisering Gids, 12-4-1996 and 5-7-1996).

$$
\text { 2. Geoworks }
$$

Geoworks derives its fame from a major achievement in the 1980s, when it developed a Macintosh like interface for the humble Commodore 64 home computer. Since then it specializes in extremely lean and compact graphical operating systems and integrated software suites. In 1990, it introduced a graphical user interface and operating system, called PC/GEOS (initially called OS/90), and suite of applications, called Ensemble, for MSDOS PCs (PC World, Nov. 1990, p. 123). Neither IBM's OS/2 nor Microsoft's Windows were yet established. Moreover, on all computers except the latest ones, Windows 3.0 was very slow. That left a windows of opportunity for a lean graphical system with a functionality that could rival Windows and OS/2 on XT or AT class PCs. To display the usefulness of its operating system, Geoworks added an integrated software suite with word processing etc. Its operating system never got the support by software makers that Microsoft got or even IBM. As hardware caught up with the requirements imposed on PCs by OS/2 and Windows, computer users were able to switch to use huge software suites from Microsoft, Lotus and WordPerfect. ${ }^{5}$ As a result, and notwithstanding winning awards for technical excellence (PC Magazine, 15-1-1991), neither PC/GEOS nor Ensemble did catch on.

Geoworks then targeted the market for handheld computers and mobile telephony, where a compact operating system is most welcome. In 1993, Tandy and Casio introduced a handheld computer using its operating system GEOS. The outstanding feature of these products was that they relied on handwriting recognition, and did not have a keyboard. Neither product succeeded in the market. In 1996, two computers were introduced that used the GEOS operating system. HP introduced the Omnigo 100: a handheld computer with handwriting recognition that does include a keyboard. It represents HP's first handheld computer that uses a

${ }^{5}$ Geoworks' home page (http://www.geoworks.com) notes that the company sold its integrated software suite to the company New Deal. 
graphical operating system, unlike its text-based MS-DOS handheld computers. The Omnigo had a very short shelf life, and is no longer supported by 1998.

Nokia introduced in 1996 a more innovative product: the Nokia 9000 Communicator, a GSM mobile telephone with a built-in handheld computer. This may well be the only significant product among those that used GEOS. Nevertheless it too seems to be doomed. In June 1998, Nokia, Ericsson, Motorola and Psion announced the creation of a joint venture, Symbian. Its main asset is the Psion operating software, EPOC 32 . By giving up control over its operating system, Psion in effect creates a separate company for software development. It thus copies more or less the business model of Geoworks and Microsoft. Psion shares rose 50\% on the day that Symbian was announced (The Financial Times, 25-6-1998). Since Geoworks may well lose its one successful customer, Nokia, to Symbian, its future looks rather bleak.

3. Microsoft tries and then tries again

The first generation of handhelds used the MS-DOS operating system. Witness the Atari Portfolio, a pioneer in 1990, and the Hewlett-Packard HP95LX, on the market since 1991. At this stage, PCs and Handheld computers promised synergies. For instance, the HP95LX included a full copy of the Lotus 1-2-3 spreadsheet. However, Microsoft went on to develop Windows. The huge system resources required to run Windows did not fit in a handheld computer. This opened a window of opportunity for rival computer manufacturers to develop their own system. Sharp developed its proprietary system (sometimes referred to as Synergy) for its Wizard series of handhelds, which is in the market since 1990. Psion developed its EPOC operating system, which became popular since the 1991 debut of its Series 3 handhelds.

The "Wintel" duopoly that dominates the PC became markedly absent from the field of handheld computers. Microsoft made at least two attempts to squeeze its 16-bit Windows 3.1 operating system into a small computer. It developed Modular Windows by 1992, an operating system aimed at interactive television and interactive multimedia players. The only product that ever appeared in the market was Tandy's VIS (Video Information System), an alternative to the Commodore CDTV and Philips CD-i video consoles for TV sets. In 1994 Microsoft discontinued Modular Windows. It also developed the Winpad operating system for handhelds, but decided by the end of 1994 to postpone its introduction to 1996. It subsequently dropped the product. Intel and VLSI formed a joint venture, the Polar project, that developed a cheap chipset for handhelds on the basis of the WinPad operating system. When Microsoft iced WinPad, Intel and VLSI cancelled their project (Computable, 16-12-1994; Byte, Aug. 1995).

A third program that Microsoft developed is Microsoft Windows for Pen Computing, an extension of Windows 3.1 for pen computers. In 1993 and 1994, Compaq sold a portable computer (the Concerto) with Pen for Windows 1.0, using both a detachable keyboard and handwriting recognition. This product met with little success in the market place, leading Compaq to abandon further plans with pen-based computing ( $C M$ Corporate, 3-6-1994, p. 20). Neither Intel nor Microsoft were able to leverage their resources and market dominance in the PC market into the handheld market. The resource requirements for Intel processors and Windows exceeded the constraints of a handheld computer. 
In the course of 1996, Microsoft did succeed in developing Windows CE, a lite version of the 32-bit operating systems Windows 95 or Windows NT, that fits the requirements of a handheld computer. In Microsoft's strategy, Windows CE is the successor of no less than three operating systems: Windows for Pen Computing, Modular Windows and WinPad. It will be used for handheld computers, navigation tools in cars, interactive television, and in household appliances. By the end of the year a slew of companies introduced handhelds using the operating system. The reason that it could succeed now is that technological development had considerably increased the resources available in a handheld computer. Compare, for example, the resources of a 1993 Psion Series 3a handheld with a second generation Windows CE 2.0 handheld introduced five years later (see the next table).

\begin{tabular}{|c|c|c|c|}
\hline \multicolumn{4}{|c|}{ Progress in resources available } \\
\hline & Psion $3 a$ & Windows CE 2.0 & Ratio (Windows / Psion 3) \\
\hline Screen resolution (pixels) & $480 * 160$ & $640 * 240$ & 2 \\
\hline RAM memory & $256<>512 \mathrm{~Kb}$ & $4 \mathrm{Mb}<>24 \mathrm{Mb}$ & 16 \\
\hline Processor speed (Mhz) & 8 & 60 & 7.5 \\
\hline Battery use (hours) ${ }^{6}$ & 120 & 15 & 0.125 \\
\hline Year introduced & 1993 & 1998 & \\
\hline
\end{tabular}

The information on battery life is a rough indication, and differs between machines. The reduced battery life of Windows CE handhelds indicates that Windows CE comes at a cost compared to Psion. So part of the progress made really results from different trade-offs made, not just from technological progress.

$$
\text { 4. The risks of a specialist strategy }
$$

General Magic, Geoworks and Microsoft are the main specialists in operating systems for handhelds. There were some others. GO was another company that sold an operating software, PenPoint for pen computing. AT\&T acquired it, and combined it with its daughter EO for the EO Personal Communicator. It closed down both companies in 1994 (Automatisering Gids, 2-6-1995). These results point to the risks of a specialist. The operating software specialist depends on others to turn the software into a marketable product. It may be difficult

${ }^{6}$ Source: Byte, Jan. 1992 (for battery life on the Psion Series 3), C:Net, 17-4-1998 (Philips Velo 500), as well as press release by Philips itself (Philips Velo 1). 
to find these others in the first place. When Palm Computing saw the market dwindle for pen computing on the basis of the GEOS operating system, it decided to develop and market its own computer. Its "Pilot" handheld computer became a runaway success, if only after U.S. Robotics got interested and acquired the company. If hardware manufacturers use an operating system, they may fail to turn it into a success. As we saw above, in 1993 and again in 1996 a pair of manufacturers introduced handheld computers that used Geoworks' GEOS operating system. None were very remarkable, except in the case of Nokia's Communicator. Exclusive reliance on one successful customer is risky: for she may change her strategy.

The one successful software specialist may turn out to be Microsoft. Since the introduction of its Windows CE operating system in 1996, no less than eight vendors licensed it to introduce a handheld computer: Casio, Compaq, Hewlett-Packard, Hitachi, LG Electronics, NEC, Philips, and Sharp.

6.

$$
\text { Multi-market scope }
$$

The position a firm takes in a network depends on the resources it contributes, and the market success of its (previous) ventures. One strategy firms use to bolster their position, both directly in market competition, and indirectly in network formation, is multi-market scope. By spreading activities in several related fields, the firm builds expertise and a brand name, it can achieve economies of scope, and it can diversify business risk. Vendors in a market can be of three types: specialists, whose scope of very limited, focused generalists, who have a wide multi-market scope of related activities, and unfocused generalists, who engage in various activities with little positive spillover effects between them.

On the side of operating software, Microsoft counts as a focused generalist, as its Windows operating system and the associated expertise now exists in various forms for various computing platforms, from the small (Windows CE) to servers (Windows NT). All other providers are specialists or unfocused generalists. These specialists are Casio (for its BOSS organizers), General Magic (for Magic Cap), and Sharp (for its Wizard line of organizers). I include Psion in this context, which did make many computers on the basis of its EPOC operating system, but it migrated from computer type to computer type, rather than developing a line of various types of computers at the same time. For the same reason, I see Geoworks as a specialist rather than a generalist. Apple is an unfocused generalist, in that its Newton system had little in common with its Macintosh operating system. 


\begin{tabular}{|c|c|c|c|}
\hline \multicolumn{4}{|c|}{ Multi-market scope advantages realised by suppliers of hardware and software } \\
\hline & Specialist & Focused generalist & Unfocused generalist \\
\hline $\begin{array}{l}\text { Operating system } \\
\text { software }\end{array}$ & $\begin{array}{l}\text { 3Com (Pilot division) } \\
\text { Casio } \\
\text { General Magic } \\
\text { Geoworks } \\
\text { Psion } \\
\text { Sharp }\end{array}$ & Microsoft & Apple \\
\hline hardware & Psion & $\begin{array}{l}\text { Casio } \\
\text { HP } \\
\text { NEC } \\
\text { Nokia } \\
\text { Philips } \\
\text { Sharp } \\
\text { Texas Instruments }\end{array}$ & 3Com \\
\hline
\end{tabular}

On the hardware side, $3 \mathrm{Com}$ is not likely to have economies of scope between the network hardware equipment that it manufactures and the Pilot. Focused generalists are companies that manufacture handhelds as well as calculators (Casio, HP and Texas Instruments), mobile telephones (Nokia and Philips), (sub)notebooks (HP, NEC) or cameras (Casio, Sharp). I ignore Apple and Compaq as these did not manufacture their own handheld computers, but subcontract them from Japanese vendors. The table suggests one striking outcome: the generalist suppliers of hardware have flocked around the Windows CE approach. Microsoft's focused generalization in software is complementary to the focused generalization in hardware from companies like Casio. The exception is Texas Instruments, which introduced its proprietary Avigo handheld, an incompatible clone of the Pilot.

7.

$$
\text { Standardization }
$$

There is an increasing amount of and support for industry standards in the handheld market. Standardization seems an important contributor to the growing demand for these machines.

On the supply side, standardization can lead to increased scale and thus lower production costs. For instance, the Psion 3 series uses a memory card similar to PC card, but not conforming to it. Due to the limited sales of these cards, their price is much higher than a PC card with similar storage capacity. If the operating system of a PDA is similar or identical to an existing operating system, existing software can be converted at little or no costs to the PDA market. This is an advantage that Windows CE machines may have over their rivals. If this leads to a larger amount of software being supplied, users may derive a higher utility from a windows CE machine than from another system.

On the user's side, standardization offers various advantages. If the operating system is familiar, learning time is cut short. Standardization makes it possible to exchange information between a PDA and the PC. Standardization also facilitates coupling a PDA to other mobile or portable devices: a mobile telephone, a digital 
camera. This process of standardization tends to increase the functionality of a handheld computer much beyond that of an electronic organizer.

In an electronic organizer, data are stored in RAM memory. RAM memory is fast, but it is also expensive and it needs a battery to keep the information stored. To store more information, cheaply and reliably, a memory card was required that stores information permanently, without a battery being required. In 1985, Japanese manufacturers combined in the JEIDA (Japanese Electronic Industry Development Association) formed a workgroup to develop a standard for memory cards. In 1989, a very large number of companies formed the Personal Computer Memory Card International Association (PCMCIA). Members include HP, Intel, Microsoft and Sharp. The PCMCIA faced an array of PC memory cards. Various manufacturers had developed cards of their own: NEC, Mitsubishi, and Atari; Fujitsu had selected the JEIDA standard (Byte, Feb. 1991). Several of these were submitted to the PCMCIA. The PCMCIA accepted the one by the JEIDA, which then became the PCMCIA standard. Version 1.0, released in 1990, defined PCMCIA cards with memory functions. Version 2.0, released a year later, added functions, such as PCMCIA modems and connections to a network. To make the standard more familiar, it was renamed into the PC Card. The result is a versatile way to expand the functionality of a portable or a handheld computer. Since products that conform to the PC Card or PCMCIA standard can be used by all portables and handhelds, whatever their operating system, suppliers of these products can realise economies of scale, which can reduce their price.

In a quest to further miniaturize computers, smaller cards than the PC Card appeared. In 1995, the company Sandisk developed the Compact Flash card. Being very small, it can be used in digital cameras, mobile telephones, and in handhelds. This is reflected by the group of companies that supports the standard, and which includes Apple, HP, Kodak, and Motorola. Some suppliers of Windows CE handhelds adopted this technology. A similarly diverse group of companies supports the alternative Miniature Card technology. They include such heavyweights as Intel, Microsoft and Philips. Not be outdone, in early 1996 Toshiba garnered support for its own standard, the Solid State Floppy Disk Card (SSFDC). As a result, the ranks which the PCMCIA association had closed around the PC Card standard, has been opened again.

Another standard that handheld and portable computers share is the IrDA, for infrared data transmission. Beaming information by means of infrared light between electronic equipment (such as computers, printers, and networks) is easier than connecting equipment by cables. A well known example of this technology is the remote control, which uses infrared light to control the TV set. Various companies, including HP, Sharp and General Magic, developed technologies for infrared transmission of data. To come to a standard, organizations including Apple, Compaq, Intel and Microsoft, joined in a non-profit group, the InfraRed Data Association. In late 1993, the InfraRed Data Association selected HP's technology as the standard, which is since then known as the IrDA. This is a vital ingredient in connecting the handheld computer to the outside world. Without standards for information content, however, a handheld can usually only exchange information with computers by the same manufacturer or the same operating system. One thing most handhelds with an IrDA connection can do is to send files to a HP printer for printing.

In order to facilitate data exchange, information content standards are required. For the most part, these standards are absent, so exchanging information is cumbersome. Handhelds are usually more economical than computers in storing files, so the format in which a file is stored (as a text, or spreadsheet, for example) usually 
differs between a handheld computer and a PC or terminal. The outside world of most handheld users consists of Windows computers, telephony networks (the GSM mobile network and the Plain Old Telephony System), corporate databases, and the Internet network. In the Internet community, the vCard and vCalendar standards provide some standardization for viewing address cards and calendar (agenda) information. By early 1997, the IETF (Internet Engineering Task Force) is involved in upgrading these standards to give them greater functionality. If both the software used by handheld computers and those used by personal computers or terminals adopt these standards, exchanging information between these products will become easier.

Another standard for data exchange is the Hand-Held Device Markup Language (HDML), which is a variety of the HTML Internet file standard for wireless Internet access. The company Unwired Planet developed this standard, which is submitted for approval by the WWW Consortium (Automatisering Gids, 18-7-1997). Geoworks is also involved in adapting Internet technology to the needs of wireless access. Several aspects of handheld computer / telephone combinations that limit the potential of wireless access is that they tend to have small screens, a small keyboard, or none at all, and a low bandwidth for data transmission. If a combination of standards evolves for wireless Internet access, mobile telephones and handheld computers can merge for combined voice and data communication needs. This may increase the usefulness of products like the Nokia 9000 Communicator, which now combine a GSM telephone and a PDA.

The operating system defines the overall functionality of a handheld. There is as yet no standard in this regard. Both the first generation and the second generation vendors of PDAs failed to set the standard for a handheld. The systems that now battle it out in the market are either completely new introductions of the third generation (the PalmPilot and Windows CE) or a strongly improved version of a first generation system (Psion's EPOC 32$)$

Most of these standards tend to increase the functionality of the product (the market creation effect) without providing a competitive benefit to the one who developed the standard (the market power effect). HP may still derive a license fee from its IrDA technology, but ownership of this technology does not give it any advantage the market place relative to other suppliers such as Sharp. As usual, the operating system used is the exception. The operating system and content standards such as vCard determine adjustment costs that programmers and customers have to make when exchanging software and content between handheld and other computers. The winner in setting standards has the lowest adjustment costs, which tends to provide a competitive advantage. This argument suggests that standards where the market creation effect dominates tend to evolve more easily than standards where the market power effect dominates. This may be one factor in explaining the early development of the PC Card and IrDA standards, as well as the late development of operating system and information content standards.

8 .

Innovators and First Movers

An innovator has all the costs and risks of developing something new and untried, but it also has the benefits of the first move. Three companies stand out as innovators of the three strands of handheld computers: the keyboard-based handheld computer, the PDA (the notetaker with handwriting recognition), and the personal communicator. These pioneers are Atari, Apple, and EO. How did they fare? 
Atari is quite a surprising participant in this market. But then Atari has had a large number of innovations. It pioneered the videogame market, it earned admiration in the 1980s for its 8-bit home computers and its 16-bit ST Macintosh-like home computers, it entered and exited the market for IBM compatible clones, and pioneered and abandoned the handheld market. In the 1990s, it found a niche in the music industry where its ST series became a standard. In 1994 it re-entered the market for videogame consoles with its Jaguar set-top box. This seems an example of flexibility where there is too much of a good thing. The company has always lacked commitment, corporate size, and market power. With such characteristics, it is unlikely that it would have been able to expand and develop its Portfolio.7

$$
\text { 2. } \quad \text { The Apple Ne wton }
$$

The rise and fall of the Apple Newton presents an interesting case of the development of the handheld market. Apple cooperated with various partners. It cooperated with Sharp for developing and producing the hardware. The microprocessor is from the British company ARM, Advanced Risc Machines. Apple forged links with SkyTel, for access to a satellite network for delivering e-mail, and Random House, to publish reference books on the Newton platform (The Economist, 30-5-1992). It cooperated with the Russian company ParaGraph International, from Moscow, on the Newton's centerpiece: its ability to read handwriting. Unlike with the Macintosh operating system, Apple licensed the Newton system. Its five licensees were Sharp Electronics, Motorola, Cirrus Logic, Siemens Private Communications Systems Group, and Kyushu Matsushita Electric (Business Week, 5-7-1993).

Upon its introduction, the Newton was expensive at \$699. It had no keyboard; data entry was exclusively by means of handwriting recognition. The disadvantage of this approach was that due to underdeveloped handwriting recognition technology, data input was tedious and error prone. Apple missed the one advantage of not having a keyboard, smaller size, by making the Newton rather bulky. Apple's plans were to upgrade the Newton, and to add varieties later. One variety considered was a tiny, 3-by-5 inch Newton notetaker (MacWorld, Sep. 1993). These measures, ironically, are those of the PalmPilot, which would later be the first popular handheld to use the Newton approach.

Before the launch, Apple created enormous expectations about its Newton. From a public relations perspective, the introduction was a resounding success. So much so, that one may forget that by the time Newton actually shipped, in 1993, there were various rivals with similar products. Tandy and Casio simultaneously launched the Zoomer, which also had no keyboard and relied on handwriting recognition. In that

7 Atari ceased activities in July 1996 (source: Global Researcher, Worldscope database). 
same pivotal year, Amstrad priced its Pen Pad organizer for \$499: cheaper than the Newton, similar features, but less powerful. Of these pioneers, Apple survived longest. But it, too, lost out to later rivals. Apple's hype turned out to be a double-edged sword. On the one hand, it quickly eclipsed its rivals. The problems its technology had, delayed the efforts by other rivals, notably, Microsoft. On the other hand, users were disappointed by the product. Reviewers ridiculed it. The Newton did not get the time to mature, perhaps exactly because Apple had created such as visionary appeal to it.

By developing the Newton from the ground up, Apple had no synergy between its Macintosh system and the PDA. Users did not have synergy either: the Newton was not an obvious extension of a Macintosh computer. Another problem for Apple is that it has little contact with the industrial computer world. Compare this to Microsoft's success in attracting industrial companies to build Windows CE machines. Apple only attracted the support of Sharp, whereas Microsoft gets support from many heavyweights in the computer and consumer electronics industry, such as Compaq, HP, NEC, Philips, Sharp, and LG Electronics. Still, Apple innovated, and its product might have worked. Its own lack of commitment to an increasingly marginal product meant that improvements came too slow and were too limited.

Apple's problems in improving and marketing the Newton, created a window of opportunity for rivals. In 1996, HP introduced its Omnigo, which uses the Graffiti software for handwriting recognition, and the GEOS operating system. Uniquely, the Omnigo also has a keyboard, so it doesn't completely rely on handwriting recognition

It was, however, the small company Palm Computing that finally did it right. In 1996, it introduced the PalmPilot handheld computer. The PalmPilot uses the one advantage of handwriting recognition: by doing away with the keyboard, the machine can be very small and cheap. It is small and light enough to fit in the pocket of a shirt. It also exchanges information with the PC literally upon a touch on a button. This is a feature computer users had long waited for. This feature also makes the exclusive reliance on handwriting recognition less of a problem as it accepts input from the PC. A user will enter most information in her personal computer. By pushing the synchronization button, she gives the command to exchange this information with the PalmPilot. The PalmPilot is for looking up information, rather than for entering texts. Its functionality is limited, but what it should do, it does, and it is cheap and compact. The features of the PalmPilot are, therefore, complementary. To illustrate its success: the PalmPilot accounted for more than 63 percent of the handheld market in 1997, up from 51.7 in 1996, and over 1 million units were shipped in 1997 (according to Dataquest, quoted in C:Net, 26-51998). The PalmPilot's success reveals that Apple's product had contradictory features: a high price but limited functionality, no keyboard and still big and heavy, advanced technology but little added value over a paper agenda.

Part of the success of Palm Computing is due to the fact that although the company was an upstart, it started with established people. Its founder, Jeff Hawkins, was involved in developing the GridPad, one of the first computers to use pen computing (Byte, September 1992). He founded Palm Computing to develop handwriting-recognition software for the GEOS operating software. The Palm Computing / Geoworks combination was used for the Zoomer handheld computer from Tandy and Casio. When this product failed commercially, Palm Computer found no better way to market its software than by developing a handheld 
computer around it. In a way, then, there is a first mover advantage: being in the business longer than anyone else can be an advantage.

The success of the Pilot has in turn attracted rivals. Texas Instruments has introduced the Avigo, which uses different technology than the Pilot but has similar features and looks. Instead of using handwriting recognition, it gets user input by having the user point at characters from a virtual keyboard displayed on the screen. Microsoft developed a variety of Windows CE for pen-based computers. In 1998, various vendors introduce products on this technology: Casio, Everex, and Philips. In the same year, Sharp introduced the Sharp SE-500 Mobile Organizer, which like the Avigo has no handwriting recognition, and which, unlike the Pilot, has a modem built-in.

One may wonder why Texas Instruments and Sharp choose to compete with the Pilot on the basis of proprietary software, rather than licensing that software. The odds are against them that they can rival the Pilot's acclaimed software, nor is it likely that they can create the level of third-party support that the Pilot now has. As the Microsoft approach shows, licensing software can attract several hardware manufacturers. One reason for 3Com's failure so far to get a similar hardware support is a feature of the Pilot noted earlier: its software is so tightly linked to the hardware, that a licensee has few options to differentiate its product. This feature of the Pilot strategy is technicaly attractive, as it explains why the product can be so compact, light, cheap and powerful, but it has the commercial disadvantage of eliminating the opportunities for rival manufacturers to use the same operating software while differentiating their product.

3. The EO Personal Communicator

In 1992, the EO Personal Communicator pioneered the combination of a communication device with a handheld computer (Business Week, 30-11-1992). AT\&T, Matsushita and Olivetti supported the company. It uses Go's PenPoint operating system, for a pen-controlled computer that has no keyboard. AT\&T supplied both the microprocessor to the EO, the Hobbit, and its AT\&T mail network. It acquired control of the company. By the end of 1994 it closed it down. AT\&T had sold less than 10.000 units all in all (Automatisering Gids, 10-1-1997). Users deemed the product too big to be really portable and too expensive, at prices between $\$ 2000$ and $\$ 3000$ (Byte, March 1993, Dec. 1994).

A second mover to this market segment is Nokia with its Nokia 9000 Communicator. Nokia made an important step in the development process when it acquired a stake in Geoworks (Byte, June 1995). In 1996 it launched the product, using Geoworks' GEOS operating system and the GSM mobile telephony platform. Unlike the first incarnation of the personal communicator, it therefore focussed on mobile telephony rather than on mobile data communication (e-mail). It is also a simpler and smaller product than the EO Personal Communicator was. It does share one characteristic: a high price. Its initial price was \$2000 (Byte, Jan. 1997). This fell to around $\$ 1000$ by August that year (Byte, Aug. 1997). Competition came from some Windows CE machines which come with a connection to a GSM telephone. Examples are the Philips Velo 1 (Byte, March 1997), the HP Omnigo / Nokia Windows CE / GSM combination, and the Ericsson set of a separate Windows CE computer and GSM telephone, which connect by an infrared link (Intermediair, 25-6-1998, 34(26): 35). In what is considered a major move in this field, Nokia, Ericsson, Motorola and Psion created their joint venture, 
Symbian, to develop technology and products that link handheld computers and mobile communication and, thus, that link data and voice communication.

The conclusion from this overview of innovators can be unambiguous. They have all been eclipsed by followers. This seems a market with second mover advantages: pioneers stumble over high set-up costs, and they tend to focus on high-technology. Rivals better understand how to avoid some pitfalls, by focussing on low costs, limited functionality, and ease of use.

9.

Partne ring

So far, we have seen three developments that drive the evolution of the handheld market: experimentation and imitation, efficiency from specialisation and multi-market scope, and standardization. An essential feature of a successful company strategy in such a context is partnering. Partnering is required to combine specialized components into a complete and usefull product. It can also be required for developing or launching a standard. And partnering shares the costs and reduces exposure to business risks due to experimentation.

Using the data sources mentioned in the references below, I constructed a database of cooperative events concerning handheld computers. The events in the database include mergers, acquisitions, alliances, joint ventures, and licensing contracts. Concerning handheld computers, it registers 61 cooperative events from 1985 to 1997. There are 78 firms that participate in these events. In these cooperative events, a firm meets other firms. If we loosely call this the size of the firm's network, we find that Microsoft had the largest network (it meets 37 firms). Some other Asian and American industrial organisations hold second and lower ranks. These firms owe their position to the fact that they participated in the PCMCIA alliance, which with 23 recorded participants, gives each firm immediately a large network. If we measure the size of a firm's network instead by the number of cooperative events, we find that again Microsoft leads, with 19 recorded events. Geoworks occupies a second place, with 11 events, and HP third with 9 events. See the table in appendix 1 for further details. Far less active were some other leading players in this market. US Robotics, Palm Computing, Sharp and Tandy participated in three events. Psion participated in two recorded events. ${ }^{8}$ Either way, Microsoft stands out for the size of its network. As the example of Psion and U.S. Robotics show, there is no immediate link between commercial success in this market and the size of the network. I do think that over the long term, a network provides benefits. First, the firm involves many who license its technology (see the number of participants of Microsoft and Geoworks), and, second, it is active in standard setting.

Apart from formal forms of partnering there is an implicit form of partnership. Both the Psion and the Pilot handhelds come with a programming language and with programming tools (see appendix 2). This created a large following of users who write and distribute programs for these machines. These supportive networks provide innovations and they fill the gaps in available software that the suppliers ignore. A community of developers is also seen as the strength of the Windows environment. Geoworks may have overlooked the importance of this development. The PC World (Nov. 1990, p. 124) notes that 'a full set of development tools

\footnotetext{
${ }^{8}$ This excludes the recent agreement with Nokia and other telecom equipment manufacturers on the Symbian joint venture, referred to in the text.
} 
[for GEOS] won't be available until the first quarter of 1991.' When it became available, its toolkit used a Sun workstation rather than a PC. This limited Geoworks' network of programmers to the lucky few who had a Sun workstation. Dataquest (1997) cites this as a possible drawback in the development of Geoworks. The availability or absence of this kind of programming support may decide about the extent of third-party support, which in turn is considered an important factor in the success or failure of an operating system.

Why would some systems, such as Windows CE, Psion and Pilot, attract greater supportive networks than others? Organizers usually did not have a programming language, and so users could not program them. The availability of programming tools and the option to add or change software of the handheld computer are thus important conditions. Suppliers use various tactics to support network formation. 3Com, which acquired U.S. Robotics, tests applications for the Pilot, and gives them a trademark if they pass. This helps customers to trust these programs, which in turn tends to increase their sales. Several vendors, such as $3 \mathrm{Com}$, Microsoft, Philips, and Psion, have websites which actively promote third party software and hardware. The level of sales of a handheld is also likely to promote the development of third-party software and hardware. This is of course one reason why Psion and Pilot attracted large support networks. Early entry also helps to build a large community of supporters, so this is an example where a first move advantage does exist.

10.

Entry Garriers and entry strategy

As the waves of entry in the period following 1990, 1993 and 1996 have shown, entry barriers in the market for handheld computers can be small. If, however, we look with hindsight at successful entry, the picture changes. The following table summarizes the entry and exit moves. 


\begin{tabular}{|c|c|c|}
\hline \multicolumn{3}{|c|}{ Entrants and their current status } \\
\hline Period & Entrants & Current status in the handheld market \\
\hline \multirow[t]{5}{*}{ 1989-1992 } & Atari & exit \\
\hline & Casio & active (hardware), exit (software) \\
\hline & HP & active \\
\hline & Psion & active (hardware and software) \\
\hline & Sharp & active (hardware and software) \\
\hline \multirow[t]{9}{*}{ 1993-1995 } & Amstrad & exit \\
\hline & Apple & exit \\
\hline & $\mathrm{AT} \& \mathrm{~T}(\mathrm{EO})$ & exit \\
\hline & General Magic & exit \\
\hline & Geoworks & active \\
\hline & IBM (Simon) & exit \\
\hline & Motorola (Envoy, Marco) & exit \\
\hline & Sony & exit \\
\hline & Tandy & exit \\
\hline 1996- & $\begin{array}{l}3 \text { Com (Pilot) } \\
\text { Microsoft } \\
\text { Nokia }\end{array}$ & active \\
\hline
\end{tabular}

The successful firms tend to be firms with a long experience in this field and in related fields. We have seen how Palm Computing and Microsoft laboured for years with very little success, before finally hitting the jackpot. A sudden stroke of genius, such as perhaps with the Atari Portfolio, is not enough. Only the persevering survive.

The importance of commitment has been stressed by proponents of a probe and learn marketing strategy (Lynn et al., 1996). A discontinuous innovation calls for costly experiments to find out where the market demand is and how the technology will evolve. Initial product launches may be commercial failures. It may take a second or third attempt before a company has it right. The initial product is a source of learning, which leads to further product development and new market segments being tried. Probing often matches a product which is not yet completely useful to a market segment that may not materialize. The aim of the probe is to acquire 
knowledge of the technology, users' response, market segments, and regulatory approval. Probe and learn is an iterated process for discontinuous innovation, with false starts, and successive approximation.

The first generation entrants in the handheld market (Casio, HP, Psion and Sharp) excelled in continuous improvements, but they largely failed in integrating breakthroughs in their product lines. Casio, HP and Sharp kept innovations outside of their main product line, while Psion integrated new technology such as a touch screen only by 1997 . These players may have underestimated the extent to which new technology enabled new functionality: think of miniaturization, touch screens, handwriting technology, and connectivity.

The discontinuous innovators of the second generation (the period 1993-1996) failed in turning technology into a product and finding a market for it. Nor did they have enough stamina. The third generation entrants, 3Com and Microsoft, succeeded in developing technology that the integrated technological breakthroughs from the previous generation, with market demand and appropiate business models. A nice quote sums up one conclusion:

'Even if you can't yet stuff all the necessary electronics into one handheld unit such as Newton, "the technology is all here,"says Martin Levetin, executive vice-president at Ram Mobile Data .. The challenge, he adds, is assembling the pieces and making commercial products out of it."' (Business Week, 12-4-1993).

Firms in deep financial and strategic trouble, such as Amstrad, Apple, and Atari, or firms that fail to develop commitment, such as AT\&T and Motorola, are unlikely to succeed in a probe and learn process. Standardization tends to eliminate the suppliers of loosing technologies, such as General Magic, but it also invites new players by reducing the technology risks for suppliers and buyers.

11. Conclusion

As the theoretical introduction of the paper hinted, the handheld market displayed a development towards networking in three levels:

Suppliers: The pioneering products tended to be the work of an individual, completely autonomous vendor. The exceptions were Atari and HP which used the MS-DOS operating system from Microsoft. The second and third generation tended to be based on collaboration efforts. Ironically, only the dominant product in the market, the Pilot, still stands as an isolated effort.

Customers: Initially, customers treated the organizer as a substitute for the paper agenda. Hence, the information contained in the machine remained isolated (the organizer as data prison). During the 1990s, PCs became a lot more widespread. Users increasingly felt the need to exchange the information between their handheld and their personal computer. Moreover, the longer a person uses a handheld computer, the larger the stock of information that it contains. These developments make it useful to exchange information between users (such as an exchange of business cards), to provide access to or contribute to the company data while on the road (mobile computing), and to exchange information between the handheld and the PC or mobile telephone (connectivity). 
Technology: connectivity of the handheld developed from an afterthought (which it was for the Psion series 3, for instance, or the Sharp Wizard), to an essential design feature (as with the Windows CE machines or the Nokia Communicator). Each newer generation tends to combine more and more complex features, functionalities and modules. For instance, the Philips Velo series stands out for including a modem, which until then had been an additional accessory. As a result, the handheld computer evolves from a standalone product towards a node in a data and voice communication network.

The table summarizes the argument.

\begin{tabular}{|l|l|l|}
\hline \multicolumn{3}{|l|}{ The trend towards networking in the handheld computer market } \\
\hline & First generation & Third generation \\
\hline Suppliers & $\begin{array}{l}\text { Individual hardware and software } \\
\text { generalists }\end{array}$ & $\begin{array}{l}\text { Collaborating specialists; alliances for product } \\
\text { development, standardization, market entry; } \\
\text { networks of programmers }\end{array}$ \\
\hline Customers & $\begin{array}{l}\text { Individual, professional users; } \\
\text { geeks }\end{array}$ & $\begin{array}{l}\text { Corporate users } \\
\text { Individual customers use the Internet to exchange } \\
\text { tips, criticisms, software }\end{array}$ \\
\hline Technology & Standalone product & $\begin{array}{l}\text { Connectivity to corporate network, telephony } \\
\text { network, Internet }\end{array}$ \\
\hline
\end{tabular}

Success seems to come from a combination of the following factors:

product features (e.g., no handwriting recognition, unless there are compensating advantages such as small size);

- connectivity (people care about information rather than about products, a handheld should connect to the information world rather than being a 'data prison');

- price (if higher than $\$ 500$ only the most mobile business users will apply. These people already tend to have a portable computer, so why would they want a handheld?!);

- business model (low price calls for efficiency by using specialization and multi-market scope; specialization calls for networking and pooling complementary strengths; treat users as partners in software development; support standards to overcome technology risks).

A successful business model calls for various strategies:

Absorb current technology so the product excels in usability. 
- Maintain consistency over time so networks can evolve consisting of users, software programmers, and suppliers of hardware peripherals (such as modems). Consistency also reduces investment costs by 'recycling' existing technology.

- $\quad$ To combine these two contradictory requirements calls for using a flexible architecture that is able to incorporate innovations, is compact and lean enough for a handheld computer, and that is backwards compatible.

- Engage in networking, so as to attract support for one's architecture in product development, standardization, and market position.

- $\quad$ Support industry-wide standards, to reduce switching costs from users and (software or hardware) suppliers.

These success factors seem to require a modular standards-based system design. Modular systems are the only practical approach today to combine complexity (the outcome when new technologies are integrated in existing systems) with dynamics (which calls for continuity with the past). In terms of Henderson and Clark (1990), the handheld market has seen radical innovations. The first generation architectures were not flexible enough to cope with new modules (such as modems, handwriting recognition software, data synchronization with the PC, the Internet). This ushered in new architectures. Radical innovations are risky, which may explain the commercial failure of the second generation experimental handhelds. The third generation vendors finally were able to provide architectures that are sufficiently flexible to accommodate innovations and that are sufficiently lean to be useful for a handheld computer.

\section{References}

Dataquest (1997) Fall 1997 Handheld Report: 1996 Results and Other Developments (http://gartner12.gartnerweb.com/dq).

Hamrick, Kathy B. (1996) The History of the Hand-held Calculator, The American Mathematical Monthly, 103(8), October 1996: 633-639.

Henderson, R.M. and K.B. Clark (1990) Architectural Innovation: The Reconfiguration of Existing Product Technologies and the Failure of Established Firms, Administrative Science Quarterly, 35: 9-30.

Lynn, Gary S, Joseph G. Morone, and Albert S. Paulson (1996) Marketing and Discontinuous Innovation: The Probe and Learn Process, California Management Review, 38(3), Spring, 8-37.

Tanenbaum, A.S. (1997) Computernetwerken, 2d ed., Schoonhoven: Academic Service.

Tirole, J. (1988) The Theory of Industrial Organization, Cambridge Mass.: MIT Press.

Vercoulen, Frank and Marc van Wegberg (1998) Market Selection versus Negotiated Selection of Standards in Internet Telephony, University of Maastricht, mimeo.

Wegberg, Marc van (1996) Architectural Battles in the Multimedia Market, in: N.W. Jankowski and L. Hanssen, eds., The Contours of Multimedia: Recent Technological, Theoretical and Empirical Developments, Luton: John Libbey Media; Chapter 3: 32-46. 
The information in this paper comes from various sources, including prominently:

Automatisering Gids

Business Week

Byte

C:Net (http://www.cnet.com/?st.co.gp.rb.cn)

Dataquest (http://gartner12.gartnerweb.com/dq/static/dq.html)

Financial Times

Semico (http://www.semico.com)

The Economist 
Appendix 1 Cooperative events about handheld computers (1985-1997)

\begin{tabular}{|c|c|}
\hline \multicolumn{2}{|c|}{ Number of cooperative events pertaining to handheld computers } \\
\hline Microsoft & 19 \\
\hline Geoworks & 11 \\
\hline HP & 9 \\
\hline Casio & 7 \\
\hline Toshiba & 6 \\
\hline Apple & 6 \\
\hline Nokia & 5 \\
\hline Motorola & 5 \\
\hline Intel & 5 \\
\hline General Magic & 5 \\
\hline Compaq & 5 \\
\hline AT\&T & 5 \\
\hline
\end{tabular}


Appendix $2 \quad$ Networks of third party suppliers, shareware, and users

\section{Palm Pilot:}

Third party software:

http://palmpilot.3com.com/software/pilosoft.html

Shareware:

http://palmpilot.3com.com/resources/shareware.html

Some online shops of accesories and software: http://palmpilot.3com.com/resources/eshopping.html

A community of Palm Pilot users and suppliers of software or add-ons (a web-ring):

http://www.webring.org/cgi-bin/webring?list\&ring=geoff

An example of third-party created innovation: these sites turn the humble Pilot into an electronic book for close to everything short of War and Peace:

http://www.webring.org/cgi-bin/webring?list\&ring=geoff

http://www.macduff.net/

Psion:

Shareware:

http://3lib.ukonline.co.uk/

\section{Windows CE:}

List of products:

http://www.microsoft.com/windowsce/hpc/partner/rguide/prodindx.asp

http://207.88.7.96:8080/velo/FMPro?-db=product\%20database.fp3\&-lay=Web\&-format=search_results .htm\&-findall

Philips supports a group of Windows CE enthousiasts (a web-ring):

http://www.webring.org/cgi-bin/webring?ring=nino;list 